\title{
The Contributions of W.D. Stevenson to the Development of Neurosurgery in Atlantic Canada
}

\author{
K. Mukhida and I. Mendez
}

\begin{abstract}
The establishment of a neurosurgical department in Halifax in January 1948 marked the beginnings of the first dedicated neurosurgical service in Atlantic Canada. The development of neurosurgery in Halifax occurred in a receptive place and time. The Victoria General Hospital, the region's largest tertiary care centre, and the Dalhousie University Faculty of Medicine were in a period of growth associated with medical specialization and departmentalization, changes inspired in part by the Flexner Report of 1910 . Atlantic Canadians during this period were increasingly looking to specialists for their medical care. Although this social environment encouraged the establishment of surgical specialty services, the development of neurosurgery in Halifax, as in other parts of Canada, was closely associated with the efforts of individual neurosurgeons, such as William D. Stevenson. After training with Kenneth G. McKenzie in Toronto, Stevenson was recruited to Halifax and established the first neurosurgical department in Atlantic Canada. From the outset and over his twenty-six years as Department Head at the Victoria General Hospital and Dalhousie University, Stevenson worked to maintain the department's commitment to clinical practice, medical education, and research. Although Stevenson single-handedly ran the service for several years after its inception, by the time of his retirement in 1974 the neurosurgery department had grown to include five attending staff surgeons who performed over two thousand procedures each year. This paper highlights the importance of Stevenson's contributions to the development of neurosurgery in Atlantic Canada within the context of the social and medical environment of the region.
\end{abstract}

RÉSUMÉ: Contributions de W.D. Stevenson au développement de la neurochirurgie dans les provinces Maritimes. L'établissement d'un département de neurochirurgie à Halifax en janvier 1948 a marqué le début du premier service spécialisé en neurochirurgie dans les provinces Maritimes. La neurochirurgie s'est développée à Halifax à un moment et en un lieu favorables. Le Victoria General Hospital, le centre de soins tertiaires le plus important de la région, et la faculté de médecine de l'université Dalhousie étaient dans une période de croissance associée à la spécialisation médicale et à la formation de départements, des changements inspirés en partie par le Rapport Flexner en 1910. Pendant cette période, les canadiens des provinces Maritimes se tournaient de plus en plus vers les spécialistes pour leurs soins de santé. Bien que cet environnement social encourageait l'établissement de services chirurgicaux spécialisés, le développement de la neurochirurgie à Halifax, comme dans d'autres parties du Canada, était étroitement associé aux efforts de certains neurochirurgiens, dont William D. Stevenson. Après avoir fait son entraînement avec Kenneth G. McKenzie à Toronto, Stevenson fut recruté à Halifax et établit le premier département de neurochirurgie dans les provinces Maritimes. Dès le début et pendant les vingt-six ans qu'il fut chef du département au Victoria General Hospital et à l'université Dalhousie, Stevenson s'est efforcé de maintenir l'orientation du département vers la pratique clinique, l'éducation médicale et la recherche. Bien que Stevenson ait dirigé seul le service pendant plusieurs années après son établissement, au moment de sa retraite en 1974, le département de neurochirurgie comprenait cinq chirurgiens qui faisaient plus de deux mille interventions par année. Cet article souligne l'importance des contributions du Dr Stevenson au développement de la neurochirurgie dans les provinces Maritimes, dans le contexte de l'environnement social et médical de cette région.

Can. J. Neurol. Sci. 1999; 26: 217-223

The neurosurgery department in Halifax was established in January 1948 as the first neurosurgical service in Atlantic Canada. Its development occurred in both a receptive place and time. The Victoria General Hospital (V.G.H.) and the Dalhousie University Faculty of Medicine were in a period of growth associated with medical specialization and departmentalization, changes inspired in part by the Flexner Report of 1910.-5 Atlantic Canadians were increasingly looking to specialists and hospitals for medical care..$^{3,4,6}$

Although the social environment of Atlantic Canada was important in facilitating the establishment of surgical specialties, the development of neurosurgery in Halifax centred around the pioneering efforts of an individual neurosurgeon, William D. Stevenson. In 1924 Kenneth G. McKenzie, whose program in Toronto became one of the first training centres in Canada, ${ }^{7-13}$ created the first neurosurgical service in Canada. After training with McKenzie, Stevenson was recruited to Halifax to establish the first neurosurgical service in Atlantic Canada. From the outset and over the next twenty-six years as Department Head at the

From the Division of Neurosurgery, Department of Surgery, Dalhousie University, Halifax, Nova Scotia.

RECEIVED DECEMBER 11, 1998. ACCEPTED IN FINAL FORM APRIL. 27, 1999.

Reprint requests to: Dr. I. Mendez, Division of Neurosurgery, Department of Surgery, Dalhousie University, Queen Elizabeth II Health Sciences Centre, New Halifax Infirmary, 1796 Summer Street, Room 3806, Halifax, Nova Scotia, Canada B3H 3A7 
V.G.H. and Dalhousie University, Stevenson worked to maintain the department's commitment to clinical practice, medical education, and research. He immediately assumed the traditional role of general surgeons in Halifax in the management of patients with central nervous system injuries, and also assumed responsibility for cases that previously had been referred to the Montreal Neurological Institute (M.N.I.) and Lahey Clinic in Boston. Although Stevenson single-handedly ran the service for several years after its inception, by the time of his retirement in 1974 the department had grown to include five attending staff surgeons who performed over two thousand surgical procedures each year.

This paper reviews the history of neurosurgery in Atlantic Canada, demonstrates the importance of Stevenson's contributions to the development of neurosurgical services, and places them in the context of the social environment of Atlantic Canada.

\section{"The Day of The Specialist"3}

Stevenson established a neurosurgical department in Halifax five years after the opening of a new building at the V.G.H., the fifteen-storey Victoria Building, on July 1, 1943 (Figure 1). ${ }^{3}$ It was the tallest hospital building in the commonwealth at that time and facilitated the segregation of hospital services that led to increased specialization and departmentalization. ${ }^{3}$ As Saint Mary's University historian Howell notes, ${ }^{3}$ for those who were intimately tied to the hospital, the opening of the new building also marked "the dawning of a new age of hospital care in the Maritimes."

The type of care the V.G.H. provided had changed since its establishment in 1857. ${ }^{3.14-17}$ Although the hospital had been originally established to provide charity medical care for the sick poor, it increasingly worked to attract more of the sick middle and upper class populations to increase its revenue., ${ }^{3,14-17}$ Over the years the hospital sought to bridge the social distance that existed between doctor and patient. This social disparity often caused patients to respond to their hospitalization by "resisting treatment, mocking authority, or in some cases absconding". ${ }^{3}$ Although individual personalities and rivalries dominated the early years of the hospital, until 1920 , the hospital culture had improved by the time of Stevenson's arrival. ${ }^{1-5,14} \mathrm{~W}$.B. Atlee, the hospital's prominent and outspoken Head of the Department of Obstetrics and Gynaecology in the early to mid-twentieth century, remarked that the 1930s were an "age of miracles": "When I hear the boys complaining about how slow we are down here in the Maritimes and how difficult it is to get things done, I refer them to the miracle of progress and expansion that has changed the hopless [sic] and pathetic situation of 1907 to the present proud achievement".!

An impetus to change at the medical school and hospital was the Flexner Report of 1910. Abraham Flexner had begun assessing North American medical schools on behalf of the Carnegie Foundation in the early twentieth century.,18 Traveling to various schools, Flexner evaluated their entrance requirements, the size and training of the faculty, the quality and adequacy of the curricula, and the relationships between the schools and hospitals. ${ }^{5}$ His review of Dalhousie was not complimentary; in Atlee's ${ }^{l}$ words, "of course we didn't stand a chance. We got so low a rating that only luck could salvage us from oblivion. What saved us was geography. We were the only medical school in the east of Canada. There simply had to be a school in this region."

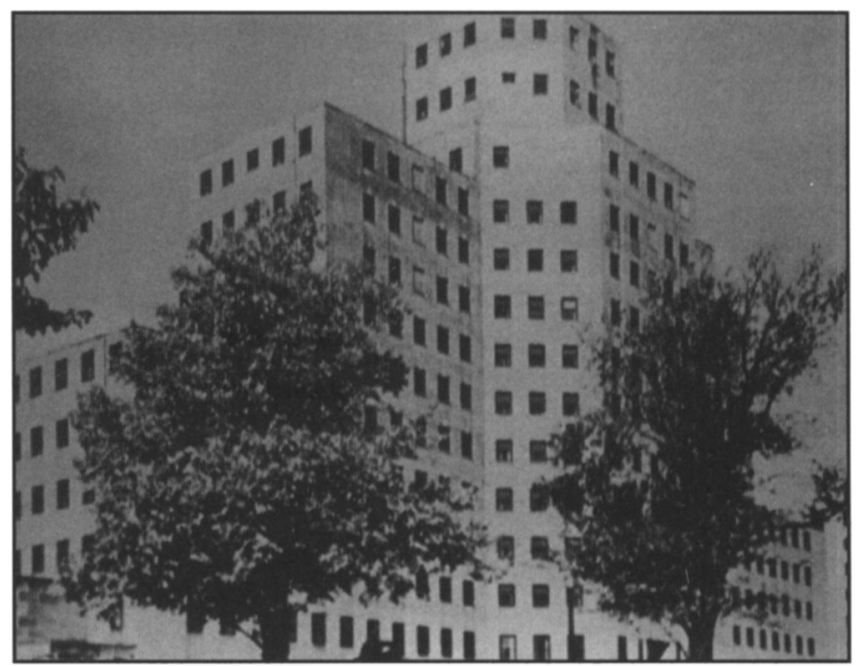

Figure 1: When the fifteen-storey Victoria Building was opened on July 1, 1943, it was the tallest hospital building in the Commonwealth. It facilitated hospital departmentalization and medical specialization.

After initial complaints by the school and hospital that the report was unfair, significant changes were made that catalyzed a process of modernization and specialization. There was expansion of the medical school and hospital. With Carnegie and Rockefeller funds a new Medical Sciences Building, medical and dental library, and public health clinic were constructed. ${ }^{15,518} \mathrm{~A}$ new addition to the V.G.H., the Private Pavilion, was built to attract more paying patients; its four floors featured sixty-seven new beds and a new $\mathrm{X}$-ray department. ${ }^{3}$ The hospital materialized its policy of modernization. New departments of anaesthesiology, gynaecology, and pathology were created. ${ }^{3}$ The rivalry that had previously characterized the surgical staff was remedied: "a growing sense of camaraderie and good will emerged". ${ }^{3}$ The medical school and the hospital's expansion mutually enhanced the other's development: "the Hospital benefited greatly from the work of many members of the Medical Faculty and the services provided by students and interns. The Medical School in turn benefited from its association with the Hospital as a location for clinical and laboratory instruction and research". ${ }^{3}$ Those changes were responsible for the increase in patient demand for surgical specialty services and public recognition of the V.G.H. as an appropriate place to obtain medical care. ${ }^{3,6,18-20}$ Growing public support for the hospital was evident in the increasing numbers of admissions. In 1909-1910 there were 1,559 admissions, but by $1929-1930$, there were more than three times that number. ${ }^{3}$ Surgery was made "safer and more pleasant for the patient" by the use of antibiotics, blood transfusions, intravenous therapies, and improved anaesthetics. ${ }^{4}$

Stevenson found a receptive environment in which to establish neurosurgical services at the V.G.H. when he came to Halifax in 1948. Atlantic Canadians were eager to have a local neurosurgery department because they had largely accepted midtwentieth century hospital therapeutics as proper. "'The era when the average individual regarded the hospital as a 'last resort' is now passed,' Superintendent C.M. Bethune told a newspaper reporter in January 1947. The modern hospital is now an essential element in the program of public welfare, the life of the community, and is an institution to serve all classes of the public". ${ }^{3}$ 
Also, the hospital was committed to supporting Stevenson's endeavours since it had already begun a process of medical specialization. In 1945, at a ceremony for the laying of the cornerstone of the Victoria Building, the Provincial Minister of Health F.R. Davis "stressed the growing interdependence of departments and specialists and the impact of recent scientific and technological innovations": "medical science... has gone beyond the comprehension of any one man. No one doctor can pretend to know all of the measures that science can provide. The day of the specialist and group medicine has arrived". ${ }^{3}$ In a hospital that was eager to departmentalize, the addition of a neurosurgical service matched the hospital's mandate.

\section{"Like Beacons on an Unfamiliar Coast"2l}

Before Stevenson's arrival there were no neurosurgeons in the Atlantic provinces. Minor neurosurgical procedures were carried out by a few general surgeons in Halifax, among them Drs. Alan Curry, the Head of the Department of Surgery, John Merritt, and Arthur Murphy. ${ }^{22}$ They dealt with emergencies, such as depressed skull fractures, cases of middle meningeal hemorrhage, and increased intracranial pressure. Some general surgeons also performed laminectomies for disc extrusion and the Frazier operation for trigeminal neuralgia. ${ }^{23}$ Major neurosurgical cases were referred to M.N.I. neurosurgeons, such as Wilder Penfield and William V. Cone, or to Harvey Cushing in Boston.

At the beginning of the twentieth century, calls for the establishment of neurosurgical services were heeded in Canada. ${ }^{7,9-10 .}$ ${ }^{12,22,24-28}$ William Osler was among the first physicians in Canada to suggest the value of surgical specialization., ${ }^{9,24,25}$ Edward Archibald, a professor of surgery at McGill University, was the first Canadian surgeon to take a systematic interest in neurosurgery and was responsible for recruiting Wilder Penfield to the M.N.I. ${ }^{8.25}$ In 1908, Archibald published a monograph entitled "Surgical Affections and Wounds of the Head" in Bryant's and Beck's American Practice of Surgery, ${ }^{8,25}$ which compared favourably with one written by Cushing in the same year. One year earlier, in his address to the Nova Scotia Medical Association, Archibald was conditionally optimistic that neurosurgery could develop as an independent specialty in Canada: "if only the internist, especially the neurologist and also the general practitioner will learn to give up their traditional pessimism with regard cerebral cases, and will work hand in hand with the surgeon, I am convinced that great results are possible of attainment". 8.25

In 1924 at the University of Toronto the first dedicated neurosurgical service in Canada was started, and McKenzie became the first neurosurgeon in Canada. He had trained intensively for one year with Cushing at the Peter Bent Brigham Hospital in Boston. ${ }^{7,9}$ Cushing, the great pioneer of modern neurosurgery, said that it was the committed individuals who founded modern neurosurgery. In his address at the opening of the M.N.I. in 1934 he described all those who had "dabbled" in neurosurgery without committing themselves to the specialty as "beacons on an unfamiliar coast". ${ }^{21}$ Cushing remarked that whereas neurologists and other physicians not long before had been deterred from recommending cerebral operations, by the time the M.N.I. opened in 1934, they asked and expected the neurosurgeon "to do the impossible". ${ }^{21}$

\section{NEURosurgery UNDER STEVENSON ${ }^{1}$}

\section{The early years}

Stevenson fitted the mould of North American neurosurgeons of the early twentieth century in pioneering the establishment of neurosurgical services in the continent. Unlike McKenzie, who had taken a more "circuitous" route to becoming a neurosurgeon, ${ }^{7}$ a more direct path to neurosurgery marked Stevenson's early medical career. After completing senior matriculation in Dunnville, Ontario, a town just outside of his birthplace, Hamilton, Stevenson studied medicine at the University of Toronto and graduated in 1937. His interest in neurosurgery was in no small part fostered by his Anatomy demonstrator, Harry Botterell, who became the Head of the Division of Neurosurgery at the University of Toronto and later Dean of the Faculty of Medicine at Queen's University. ${ }^{9}$ After completing four years of general surgery training with Dr. William Gallie, the Head of the Department of Surgery at the University of Toronto, and one year of training with Dr. Edward Archibald, the Head of the Department of Surgery at McGill University, Stevenson was exposed to neurosurgery by serving with the Canadian military during the Second World War. He spent two years with the Canadian Mobile Neurosurgical Unit in continental Europe and the Canadian Neurological and Plastic Surgery Hospital in Basingstoke, England. After the war, he practiced surgery in Hamilton with his father, a general surgeon, but also received referrals for neurosurgical consultations. Stevenson's interest in pursuing further neurosurgical training became firm, and it was Botterell who introduced him to McKenzie.

Towards the end of his training, Stevenson was approached by Dr. Clyde Marshall, who was recruiting a neurosurgeon for the V.G.H. on behalf of the Nova Scotia Minister of Health. Stevenson was attracted to Dalhousie University for the opportunity of an academic position. Upon deciding to leave Ontario, Stevenson was frequently asked by his peers and friends, "you're surely not going down there, are you?" (Stevenson, personal communication) (Figure 2).

Stevenson initially had a warm reception in Halifax. The establishment of a neurosurgical service was supported by prominent members of Dalhousie University, such as its president, Alexander Kerr, Dean of the Faculty of Medicine, Harold Grant, and the V.G.H. Superintendent, C.M. Bethune. Even Dr. Alan Curry, the Head of the Department of Surgery, allowed that "well, maybe, there might possibly be room for a neurosurgeon here". ${ }^{22}$ Donald Carruthers, the neurosurgery department's first operating room (O.R.) nurse, recollects that Atlantic Canadians were pleased to discover that a neurosurgeon would be operating locally. Many patients were already making trips to Montreal or Boston for elective or complex procedures that the local general surgeons could not handle.

Stevenson was worried about the opinion of some senior neurosurgeons in Toronto and Montreal who talked about "some young upstart" going to Halifax to start a new service and divert patients from established centres. ${ }^{22}$ This fear was unfounded since Stevenson had McKenzie's "blessing," and Penfield

\footnotetext{
*The information presented in this section is based on references 22, 29-32, and personal communication from Stevenson and Carruthers.
} 


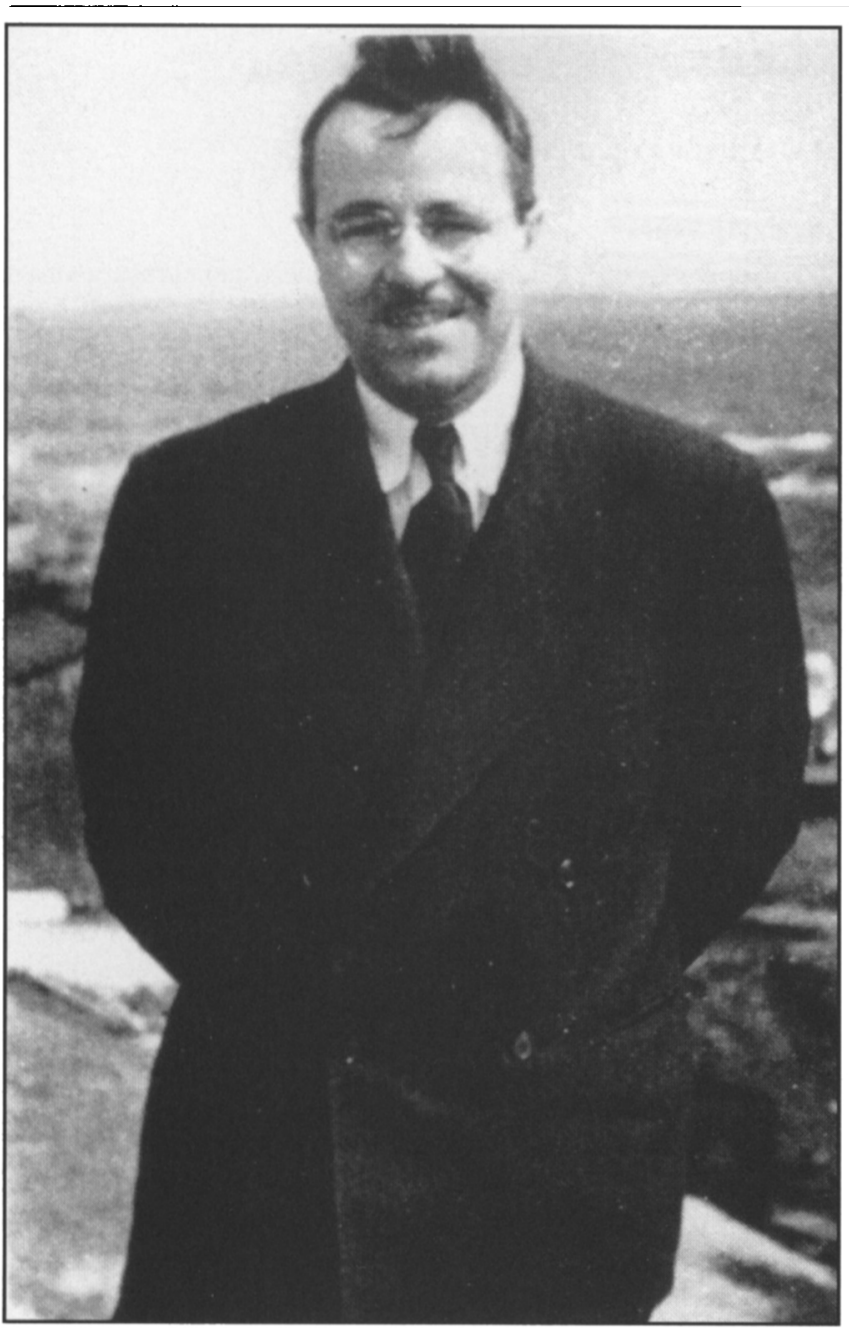

Figure 2: A youthful Dr. William D. Stevenson, $M D, M S, F R C S(C)$, Head of the Department of Neurosurgery, Dalhousie University 1948 1974. Soon after his arrival in Halifax he developed Atlantic Canada's first dedicated neurosurgical service.

referred one of Stevenson's first patients, a clergyman from New Glasgow suffering from trigeminal neuralgia. The family physician wanted to send him to Montreal, but Penfield asked him, "why send your patient all the way up here, when there is a man now in Nova Scotia perfectly capable of looking after him?" (Stevenson, personal communication).

When the neurosurgery service began in January 1948 it had only a few beds in the Alexandra wing of the V.G.H. All operating had to be done in the afternoon after the general surgeons had finished for the day. This meant that for the first several months Stevenson and his housestaff operated well into the evenings. From the outset, relations with general surgery seemed strained. ${ }^{22}$ There were constant conflicts of interest. Dr. Curry, "instead of helping [neurosurgery] with staff, equipment and other matters... seemed to begrudge any new development [neurosurgery] managed to get". ${ }^{22}$ The tension, Stevenson ${ }^{22}$ explains, "culminated on the golf course one day":

he [Dr. Curry] and I were playing with Carl Stoddard, and Dr. Curry was complaining about a nurse or two who had been assigned to our O.R. - I suppose at the expense of the General
Operating Room Suite. I finally said to him, "Dr. Curry, if you would pay more attention to building up your own service instead of running mine down, we would get along better"...but we didn't. Some general surgeons resented the service because they wanted to keep to themselves the responsibilities and revenue that they previously held in the management of patients with neurosurgical injuries. Others were opposed to surgical specialization of any kind, such as John G. MacDougall, a Professor of Surgery between 1928 and 1949, who was "profoundly opposed to specialization, and pulled no punches in saying so". 19 A surgeon worthy of the name, he thought, would be able to perform any surgical procedure. Relations were strained with other departments. Neurosurgeons carried out invasive neuroradiological procedures until 1968, since radiologists in Nova Scotia had a fixed salary and were not eager to perform additional procedures without extra pay. With the introduction of Medicare and the feefor-service salary system, radiologists "expressed a desire to take over all of the neuroradiological procedures". ${ }^{32}$ The radiologists thought "that they were now better trained, [and] could provide a better service." Neurosurgery compromised and procedures were divided between both departments. Stevenson expected that this new relationship would lead to the acquisition of new equipment, better service, and to a "smoother running situation". 32 Unfortunately, no new equipment was obtained and the provision of neuroradiological procedures became less efficient or delayed. Stevenson was a persistent advocate for a neuroradiological service when, as almost invariably occurred, "the needs of main $x$-ray and of cardio-vascular radiology etc. etc. [were] placed before those of neuroradiology which as far as radiology in general [was] concerned seems to us [neurosurgery department] to be relegated to the back waters". ${ }^{32}$

Despite these adversities, Stevenson's vision of neurosurgery in Halifax was clear and he spent the next twenty-six years as department head working to materialize it. Stevenson followed Eban Alexander's philosophy that medical education is like a milking stool with three legs: clinical service, medical education, and research. ${ }^{33}$ Stevenson aimed to develop an exemplary neurosurgical service with three strong legs.

As the department's lone neurosurgeon until 1955, Stevenson was assisted by Drs. Paul Nonamaker, Jack Charman, and Gordon Bethune. They were the first residents to rotate through neurosurgery as part of their general surgery training. Neurosurgery began with less than ten beds in the old wing of the V.G.H. until the new Victoria wing was opened in 1948. The accommodations were much improved in the new wing; up to fifteen patients could be cared for by one nursing team. Operations were carried out in a neurosurgical-dedicated O.R. on the twelfth floor, neuroradiological procedures on the third.

Carruthers, the first neurosurgical operating room nurse, "remembers well the demands [on the department members] in those early years"3 (Figure 3). Carruthers had trained at the V.G.H. School of Nursing and had served in the Canadian Army Medical Corps during World War II. He returned to the hospital and was sent to Toronto in December of 1947 to learn neurosurgical nursing techniques with McKenzie, Botterell, and Stevenson. Carruthers became the O.R. scrub nurse and Evelyn Pyle, who had also trained in Toronto, assumed nursing responsibilities for the ward and post-operative care. Carruthers admits that he was not certain what he was expected to do in the new department. Although he learned much during his time in 
Toronto, he concedes that "a lot of learning also had to be done on the job" (Carruthers, personal communication). He also recounts that the department members worked hard; there were occasions when he was unable to leave the hospital grounds for weeks because the backlog of patients requiring operations kept him and Stevenson busy every day of the week.

During his first seven years in Halifax, Stevenson was the only neurosurgeon in the Atlantic provinces. Occasionally a call would come from another Maritime centre where an emergency required neurosurgical attention. ${ }^{22}$ One evening, Stevenson received an emergency call from Moncton. Stevenson, his wife, and Carruthers immediately drove the ten hour trip to New Brunswick to perform the first neurosurgical procedure in that province. Stevenson also remembers a trip to attend to another neurosurgical emergency that occurred not long after the department opened. Stevenson and Carruthers gathered their instruments and flew to Summerside, Prince Edward Island (P.E.I.) in a ten-seat Lockheed airplane to manage a patient with a head injury. Stevenson performed burr holes for an acute subdural hemorrhage with excellent results. That visit "got the department off to a good start in P.E.I.". ${ }^{22}$ Subsequent trips to the island included a two-day trip in which Stevenson performed a lobotomy in six patients who were too disturbed to consider bringing them to Halifax.

\section{Growth}

The department soon outgrew the space available in the Victoria Building. Patients had to be moved to the solarium or other wards in order to make more beds available. It was not until 1955 that neurosurgery moved to the more spacious environment of the third floor of the Private Pavilion, which had two neurosurgical O.R.s, twenty-two beds dedicated to neurosurgery, and a neuroradiology facility. The same year, a second neurosurgeon, Harold Tucker, and a neuroradiologist, Richard James, joined the service. Weekly clinical seminars with Neurology, Pathology, Anatomy, and Physiology started, as well as biweekly rehabilitation conferences with Physical Medicine. In Stevenson's view, ${ }^{22}$ "things seemed to be falling into shape."

The department continued to expand, and by April 15, 1967 the Centennial Wing of the V.G.H. was opened, "one hundred years to the day that the first patient was admitted to the City and Provincial Hospital". ${ }^{3}$ Almost five hundred new beds were added to the surgical floors, a thirty-five per cent increase from 1966. As Howell ${ }^{3}$ notes, "neurosurgery was one department that clearly benefited from the opening of the new wing[; a] new neurosurgical section was designed as a completely self-contained unit, with all the necessary treatment and diagnostic services easily accessible to each other on a single floor." This was due in no small part to Stevenson who was intimately involved with the architectural planning of the unit between 1963 and 1967. Carruthers proudly notes that the unit was a model for other Canadian services at the time. By the late 1960s, the department had grown to include another two new neurosurgeons, Stuart Huestis and Roland Langille. The expanded service could then handle over six hundred operations per year. ${ }^{29}$ During the 1970s, William Howes and Renn Holness joined the service. ${ }^{29}$

\section{Residency program}

Stevenson was able to establish a "balanced" and "high standard" residency program at Dalhousie University. ${ }^{32}$ Medical education was one of the "legs" of his vision. In developing the service, he explains,

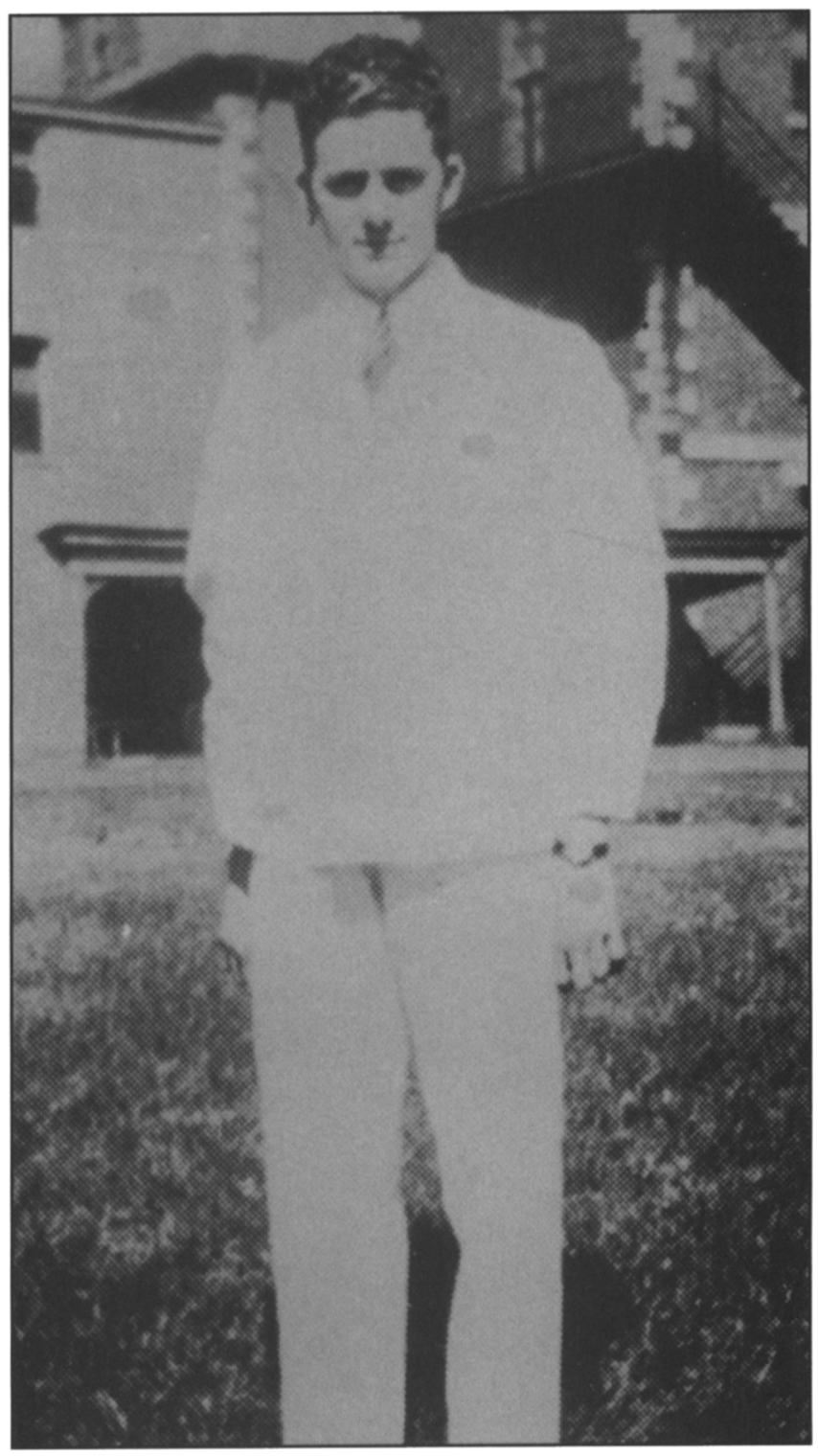

Figure 3: Donald Carruthers, the V.G.H.'s first neurosurgical operating room nurse. Carruthers trained at the V.G.H. School of Nursing and served in the Canadian Army Medical Corps during World War II. He returned to the hospital to help develop the neurosurgical service with Stevenson.

it was our intention from the beginning to select outstanding students, see them through the fundamentals of their training locally and then, before joining staff either before or after their Fellowship examinations, to see that each had an opportunity to do some training elsewhere so that he might bring back new ideas and techniques to benefit the whole Department. ${ }^{32}$

Postgraduate teaching began as soon as the department opened. For the first few years, most of the residents were from general surgery and spent no more than six months rotating through the service. Stevenson worked to ensure that a training program existed for those who were interested in pursuing dedicated neurosurgical training. The program included one year of general surgery and four years of neurosurgery. Residents were exposed to a variety of neurosurgical procedures and participated in weekly interdepartmental seminars and monthly journal club 
meetings. Provisions were made for residents to attend additional training courses and neurosurgical conferences within and outside of Canada, and Stevenson encouraged his residents to further their training at other neurosurgical centres through McLaughlin fellowships.

As part of his academic duties, Stevenson was committed to undergraduate medical education. In 1962, he conducted a nation-wide survey of the status of neurosurgery in undergraduate medical curricula. ${ }^{32} \mathrm{He}$ found that the neurosurgical department in Halifax spent more time teaching undergraduates than other centres in Canada. He continually enhanced the neurosurgical component of the Dalhousie curriculum through intense participation in medical education conferences, notably the Workshop of Neurosurgical Program Directors of Canadian and American medical schools.

\section{Research}

Stevenson regretted that the weakest leg of his vision was the department's development of a research program. Although admittedly not a laboratory researcher himself, he strongly encouraged department members to pursue research and bring new ideas back to the neurosurgical service. As the only neurosurgeon in Atlantic Canada for a number of years and Department Head for all of his twenty-six years of clinical practice in Halifax, Stevenson found it impossible to devote much time to research. As he explains, ${ }^{22}$ "perhaps a certain inherent laziness, or possibly the lack of a colleague in my own Department to push me, resulted in my publishing relatively few papers over the years." However, there was only a modest basic science research program in the Maritimes when Stevenson arrived in Halifax to complement his neurosurgical interests. Neuroscience research in the Maritimes was modest until the 1960s when John Szerb came from England to join the Department of Physiology and Biophysics to continue his work on acetylcholine function in the brain, and Graham Goddard joined the Department of Psychology to work on kindling. ${ }^{34-35}$ Nevertheless, Stevenson was able to pursue some laboratory research once Tucker had been recruited to the service. One of the projects they worked on with the cooperation of the Physiology Department was related to Tucker's work with hydrocephalic children begun during his training at the Boston Children's Hospital. They attempted to shunt cerebrospinal fluid of hydrocephalic dogs into the gall bladder; the attempt to make the dogs hydrocephalic in the first place met with only mediocre results, and to keep the fluid in the gall bladders met with even less success.

The department in those early years was able to pursue a number of clinical studies. ${ }^{36-37}$ Stevenson learned that an early cause of deafness in children was meningitis during infancy or early childhood, most likely because of the formation of adhesions around the auditory nerve in the posterior fossa. The introduction of air into the posterior fossa via a pneumoencephalogram was found to relieve the deafness sometimes. He treated a few children at the local School for the Deaf but obtained no definitive results. Stevenson also worked with Gordon Bethune of the General Surgery Department to study the efficacy of total hypophysectomy as a palliative treatment for recurrent breast cancer and presented their paper at the Annual Gallie Club meeting in Toronto in $1955 .{ }^{37} \mathrm{He}$ also collaborated with Walter Leslie in the Department of Neurology on six cases of paediatric hemispherectomy, and in 1957 conducted a follow-up study of twen-

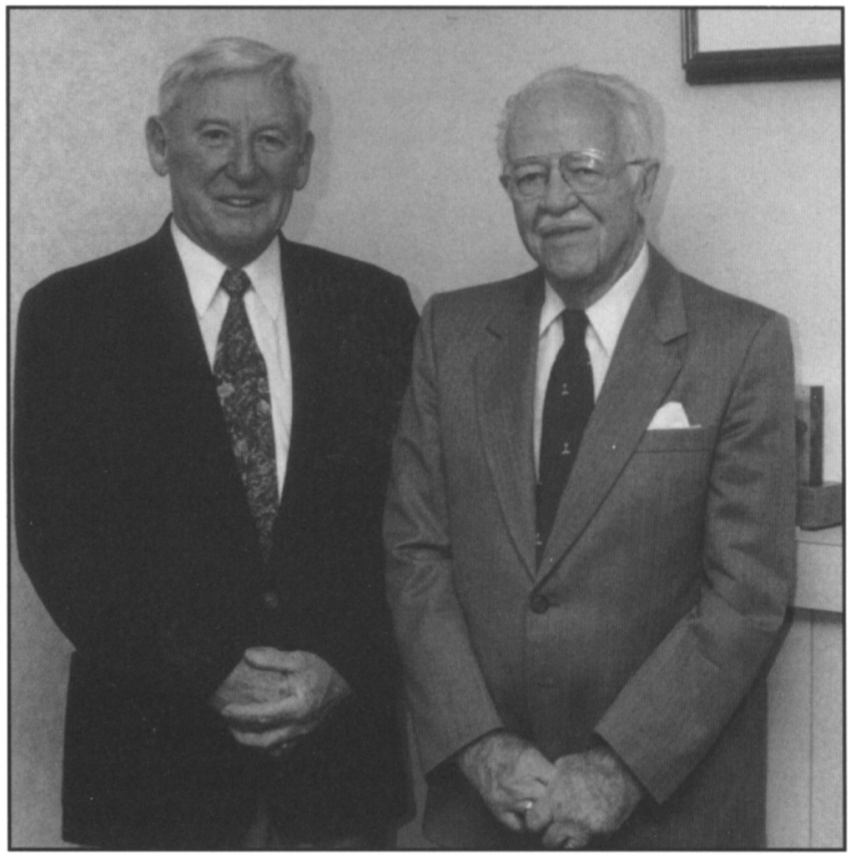

Figure 4: Dr. William Stevenson and Dr. Stuart Huestis, the first two Heads of the Department of Neurosurgery, Dalhousie University (1998).

ty-five cases of thoracolumbar sympathectomy for hypertension.

In the 1960s, neurosurgeons were increasingly involved with public health issues, and Stevenson was no exception. ${ }^{11}$ In 1962, Canadian neurosurgeons lobbied the federal government to improve social support services for people with neurological disorders. ${ }^{11}$ Later in the 1960s, they advocated measures to prevent head injuries in traffic accidents. ${ }^{11}$ Stevenson had made a similar plea ten years earlier in his 1957 review on head injuries in traffic accidents in The Nova Scotia Medical Bulletin ${ }^{38} \mathrm{He}$ urged physicians to educate their patients about the use of automobile safety devices and to advise them of any medical conditions that could render them unfit to drive. He encouraged his colleagues to work with government regulating agencies to develop driving standards and he pushed for more research into the causes and prevention of traffic accidents.

\section{Conclusions}

In Lewis Carroll' $\mathrm{s}^{39}$ Alice's Adventures in Wonderland, Alice comes across the Cheshire cat sitting in the bough of a tree. "Cheshire-Puss," Alice timidly calls out to the cat, "would you tell me, please, which way I ought to go from here?" The cat responds, "that depends a good deal on where you want to get to." In a similar fashion, the decisions Stevenson made as Department Head and the guidance that he provided to the first neurosurgical service in Atlantic Canada were dependent upon the vision he had concerning the direction he wanted the service to take. Stevenson worked to ensure that the service achieved high standards in clinical care, medical education, and research. The successes of the neurosurgical department to overcome challenges from other departments and the administration were largely the result of Stevenson's and his colleagues' perseverance. It is clear that Atlantic Canada in the mid-twentieth century was a receptive place for the establishment of neurosurgery. It is also clear that Stevenson's individual efforts were responsible for the 
development of neurosurgery in Halifax. Stevenson was not only able to care for thousands of people over his twenty-six years of clinical practice, but he also left a department that has swelled to include six attending staff surgeons and a thriving research and residency program. The last words of this paper deservedly belong to Stevenson himself, whose comments after his retirement in 1974 typified his vision of the service's continued progress: "knowing that the Department is in capable hands and seeing the progress you are making year by year pleases me greatly and I have every reason to feel confident that the future holds bigger and better things"22 (Figure 4).

\section{ACKNOWLEDGEMENTS}

The authors thank Dr. W.D. Stevenson, Mr. D. Carruthers, Dr. R.O. Holness, and Dr. T.J. Murray for providing sources of information for this paper.

\section{REFERENCES}

1. Atlee HB. Dalhousie Medical School, 1907 - 1957. Dal Med J 1958; 11:21-33.

2. Cameron I. One hundred years of Dalhousie. Dal Med J 1967; 21: 5-9.

3. Howell CD. A Century of Care. Halifax: Victoria General Hospital, 1988.

4. MacKenzie KA. A Century of Medicine in Nova Scotia. Nova Scotia Med Bull 1953; 32: 290-295.

5. Murray TJ. The Visit of Abraham Flexner to Halifax Medical College. Nova Scotia Med Bull 1985; June: 34-41.

6. Rice TB. The Doctor's Dilemma. Nova Scotia Med Bull 1950; 29 : 183-184.

7. Alexander Jr. E. Kenneth George McKenzie, Canada's first neurosurgeon. J Neurosurg 1974; 41: 1-9.

8. Feindel W. Highlights of neurosurgery in Canada. JAMA 1967; 200: 853-859.

9. Findlay JM. Neurosurgery at the Toronto General Hospital, 1924 1990: Part I. Can J Neurol Sci 1994; 21: 146-158.

10. Findlay JM. Neurosurgery at the Toronto General Hospital, 1924 1990: Part 2. Can J Neurol Sci 1994; 21: 278 - 284.

11. Morley TP. Some professional and political events in Canadian neurosurgery. Can J Neurol Sci 1985; 12: 230-235.

12. Turnbull F. Neurosurgery in Canada. Surg Neurol 1974; 2: 81-84.

13. Weir BK. Development of neurosurgery in Canada. Aust N Z J Surg 1988; 58: 929-936

14. Stewart R. The Victoria General Hospital - glimpses of the past. Dal Med J 1968; 21: 51-55.

15. Dunsworth FA. An Outline of Psychiatric Care in Nova Scotia. Nova Scotia Med Bull 1980; April/June: 61-65.
16. Ernst WA. The History of Urology in Nova Scotia. Nova Scotia Med Bull 1981; April/June: 47-49.

17. Marble AE. Surgeons, smallpox, and the poor. Montreal and Kingston: McGill - Queen's University Press, 1993.

18. Waite P. The lives of Dalhousie University, Volume I. Montreal Kingston: McGill - Queen's University Press, 1993.

19. Atlee HB. In memoriam: John George MacDougall. Nova Scotia Med Bull 1950; 29: 186-189.

20. Pollett WE. The Best of Times and the Worst of Times. Nova Scotia Med Bull 1961; 40: Editorial.

21. Cushing H. Foundation Lecture - Neurosurgery. In: Montreal Neurological Institute. Neurological Biographies and Addresses. London: Oxford University Press, 1936: 17-36.

22. Stevenson WD. Neurosurgery in Halifax, a personal account Unpublished paper 1986.

23. Janes RM. Memories of forty-five years in surgery. Dal Med J 1961; 13: $9-13$.

24. Canale DJ. William Osler and "the special field of neurological surgery." J Neurosurg 1989; 70: 759-766.

25. Feindel W. Neurosurgery at the Montreal Neurological Institute and McGill University Hospitals. Neurosurgery 1996; 39: 830-839.

26. Findlay JM. William M. Lougheed and the development of vascular neurosurgery at the Toronto General Hospital. Can J Neurol Sci 1993; 20: 337-340.

27. Parkinson D. Early history of neurosurgery in Manitoba: threads in the tapestry of world neurosurgery. J Neurosurg 1995; 82: 900 906.

28. Tator CH. New Division of Neurosurgery at Toronto Hospital. Surg Neurol 1991; 36: 378 - 379.

29. Dalhousie University/Victoria General Hospital. Department of Neurosurgery Annual Reports 1956-1957, 1958-1962, 19681970, 1971-1972, 1973-1978, 1989-1990.

30. Dalhousie University/Victoria General Hospital. Department of Neurosurgery Accreditation Survey 1972.

31. Dalhousie University/Victoria General Hospital Department of Neurosurgery. Letter from Dr. W.D. Stevenson to W.B.C. Robertson, Director, Division of Public Hospitals, Re: Standards for Neurosurgery 1972.

32. Dalhousie University/Victoria General Hospital Department of Neurosurgery. Report to the Hospital Administration 1974.

33. Alexander Jr E. Perspective on neurosurgery. J Neurosurg 1967; 27 : 189-206.

34. Jasper HH. The early development of neuroscience in Canada. Can J Neurol Sci 1985; 12: 221 - 229.

35. Szerb JC. Neurosciences at Dalhousie: past, present and future. Dal Med J 1997; 25: 45 - 48.

36. McKletchie NGB, Stevenson WD. Allergic encephalitis. CMAJ 1957; 26: 208 - 210.

37. Saunders RLDeCH. Medical research at Dalhousie. Dal Med J 1958; $11: 50$ - 75.

38. Stevenson WD. Head Injuries in Relation to Traffic Accidents. Nova Scotia Med Bull 1957; 36: 84 - 88.

39. Carroll L. Alice's Adventures in Wonderland. New York: Random House, 1955. 